\title{
Biodegradation of DDT by Co-cultures of Pleurotus eryngii and Pseudomonas aeruginosa
}

\author{
Diana Maulianawati ${ }^{1}$, Adi Setyo Purnomo ${ }^{2 *}$, Ichiro Kamei ${ }^{3}$ \\ ${ }^{1}$ Department of Aquaculture, Faculty of Fisheries and Marine Science, Borneo Tarakan University, Tarakan, Indonesia \\ ${ }^{2}$ Department of Chemistry, Faculty of Science and Data Analytics, Institut Teknologi Sepuluh Nopember, Surabaya, Indonesia \\ ${ }^{3}$ Department of Forest and Environmental Science, Faculty of Agriculture, University of Miyazaki, Miyazaki, Japan
}

\section{ARTICLE INFO}

Article history:

Received October 7, 2020

Received in revised form June 10, 2021

Accepted June 30, 2021

\section{KEYWORDS:}

Bioremediation,

Biodegradation,

Pleurotus eryngii,

Pseudomonas aeruginosa,

DDT

\begin{abstract}
Dichloro-diphenyl-trichloroethane (DDT) is a synthetic insecticide that widely used around the world, which has a negative effect on human health and the environment. The objective of this research was to investigate the ability of bacterium Pseudomonas aeruginosa in co-culturing with white-rot fungus Pleurotus eryngii to degrade DDT. The various volume of $P$. aeruginosa (1 $\mathrm{ml} \approx 1.5 \times 10^{9} \mathrm{CFU}$ ) were added into $10 \mathrm{ml}$ of $P$. eryngii culture for a 7-days of incubation. Approximately $82 \%$ of degradation of DDT were obtained from cocultures with the adjunct of $10 \mathrm{ml}$ of $P$. aeruginosa during the 7-day incubation period, which had the best ratio of optimization of 0.57 . The confrontational assay showed that $P$. aeruginosa gave no effect on the growth of $P$. eryngii $(0.39$ cm/day). DDD (1,1-dichloro-2,2-bis(4-chlorophenyl) ethane), DDE (1,1-dichloro2,2-bis(4-chlorophenyl) ethylene) were detected as metabolic products from the DDT degradation by co-cultures bacterium $P$. aeruginosa and fungus $P$. eryngii. This study indicated that bacterium $P$. aeruginosa can be used to enhance DDT degradation by whire-rot fungus $P$. eryngii.
\end{abstract}

\section{Introduction}

An increasing population has resulted from the industrialization grew rapidly in consort with an accumulation of synthetic chemical. Extensive agriculture has massively used pesticides to solve the attack of pests and to control insects that causing malaria, dengue, and plague (Sudaryanto et al. 2007). Organochlorine pesticides (OCPs) are the primary substance in the manufacture of pesticides, which 1,1,1-trichloro-2,2-bis(4-chlorophenyl) ethane (DDT) was among them. DDT was one of the persistent organic pollutants (POPs), which was banned since the 1970s. DDT is a dangerous compound, and all of the residues have low levels of decomposition, thus that it becomes one of the serious threats that can endanger the environment and humans. The depositions of DDT and its metabolites absorbed onto soils, sediments and accumulate in animal tissue. Due to this fact, the contamination of DDT has caused significant concern in environmental and food safety.

\footnotetext{
* Corresponding Author

E-mail Address: adi_setyo@chem.its.ac.id
}

The most practical, safe, efficient, and economical method that is proven to be the most promising today is biodegradation. This method can degrade a compound to be less or non-toxic. Fungi and bacteria are very often used in the biodegradation process. Many studies show the successful use of various types of fungi and bacteria to degrade DDT or toxic compounds. Both are used separately or in cocultures. Determination of optimal biodegradation conditions in a laboratory-scale through controlled and manipulation systems has provided essential information to distinguish between biotic and abiotic processes, thelength of time of degradation, secondary metabolite products, and different degradation pathways. Recently, wood-rot fungifrom group whiterot fungi (WRF) such as Ganoderma lingzhi (Boelan and Purnomo 2019), Xerocomus chrysenteron (Huang and Wang 2013), Trametes versicolor U97 (Sari et al. 2013), Phanerochaete chrysosporium (Purnomo et al. 2008; Zheng et al. 2012), Pleurotus ostreatus (Purnomo et al. 2010a, 2017a), Pleurotus eryngii (Purnomo et al. 2019a), Phlebia lindtneri, and Phlebia brevispora (Xiao et al. 2011), Stenotrophomonas sp. (Gilligan et al. 2003) as well as brown-rot fungi (Purnomo et al. 2010c, 
2011a, 2011b) could degrade $30-70 \%$ of DDT for 7-60 days incubation period, which relatively consumed long incubation times. Therefore, improvement and development of biodegradation methods using fungus need to be prepared.

The use of surfactants to enhance the biodegradation process of organic pollutant compounds has shown significant results. Several types of synthetic surfactants such as Tween 80 (Gonzalez et al. 2018), Triton X-100 (Villa et al. 2010), Tween and Brij combination (Rios et al. 2012), mixed surfactant (SDBS-Tween 80; Wang et al. 2018), rhamnolipid, sophorolipid, and trehalose lipid (Teh and Hadibarata 2014) showed the ability to enhance degradation of DDT and pyrene on contaminated soil and water. However, the use of synthetic surfactants has caused another problem, such as the presence of residues, which can lead to an increase in the potential for toxicity, which is harmful to human health and the environment (Purnomo et al. 2019c, 2020c). Thus, biosurfactants could be used as an alternative to enhance biodegradation because they were easily degraded, low toxicity (generally non-toxic), and can be produced from substrates of low economic value or waste (Wahyuni et al. 2017). A lot of research literature showed that the use of biosurfactants has a sufficient ability to improve the biodegradation process (Nawfa et al. 2019).

Biosurfactant-producing bacteria have increased the ability of fungi to degrade DDT in co-cultures. The co-cultures of $P$. eryngii and Ralstonia pickettii (Purnomo et al. 2019a), P. ostreatus and Pseudomonas aeruginosa, P. ostreatus, and Bacillus subtilis (Purnomo et al. 2017a), G. lingzhi and B. subtilis (Boelan and Purnomo2018), G. lingzhiand P.aeruginosa(Boelanand Purnomo 2019), P. brevispora and B. subtilis (Purnomo and Fajriah 2017), Fomitopsis pinicola and B. subtilis (Sariwati et al. 2017), F. pinicola and P. aeruginosa (Sariwati and Purnomo 2018), F. pinicola and $R$. pickettii (Purnomo et al. 2020a), Daedalea dickinsii and $R$. pickettii (Setyo et al. 2018) have been effective in degrading large amounts of DDT about $70-100 \%$. Although some co-cultures of surfactant-producing bacteria and fungi were able to lessen large quantities of DDT, the metabolite compounds produced from the process still have high levels of toxicity such as DDE and DDD. However, no information has been reported about the bioremediation of DDT by cocultures of $P$. eryngii with $P$. aeruginosa, and a broader assessment of the degradation of DDT by co-cultures is needed to get the best combination of co-cultures in the DDT biodegradation process.

\section{Materials and Methods}

\subsection{Material}

P. eryngii NBRC 32798 and $P$. aeruginosa NBRC 3080 were purchased from NITE Biological Resource Center, NBRC; Chiba, Japan. Pyrene, DDT, DDD (1,1-dichloro-2,2-bis(4-chlorophenyl) ethane), DDE (1,1-dichloro-2,2-bis(4-chlorophenyl) ethylene), and DDMU (1-chloro-2,2-bis(4-chlorophenyl) ethylene) were provided from Tokyo Chemical Industry Co. (Japan). Methanol, sodium sulfate anhydrous, and dimethylsulfoxide (DMSO) were obtained from Merck, Millipore (Germany). $N$-hexane and acetone were purchased from Anhui Fulltime Specialized Solvent and Reagent Co., Ltd. (China).

\subsection{Cultures Growth Preparation}

The stock of $P$. eryngii was retained on potato dextrose agar plates (PDA, Difco, UK) that had been incubated at $30^{\circ} \mathrm{C}$. The $1-\mathrm{cm}$ diameter of mycelium was conveyed into $10 \mathrm{ml}$ potato dextrose broth (PDA, Difco, UK) medium in a $100-\mathrm{ml}$ Erlenmeyer flask. $P$. eryngii was furthermore pre-incubated for 7 days at $30^{\circ} \mathrm{C}$. One colony of $P$. aeruginosa were inoculated on nutrient agar (NA, Difco, UK) incubated at $37^{\circ} \mathrm{C}$ for stock culture. One colony of bacteria was inoculated into $100-\mathrm{ml}$ Erlenmeyer flasks containing $50 \mathrm{ml}$ nutrient broth (NB, Difco, UK). P. aeruginosa were incubated for $21 \mathrm{~h}$ at $37^{\circ} \mathrm{C}$ with a shaker $(11 \times \mathrm{g}$; Purnomo et al. 2013, 2014, 2017b).

\subsection{Biodegradation Experiment and Metabolite Analysis}

After 7 days pre-incubation of the P. eryngii, the different concentrations of $1,3,5,7$, and $10 \mathrm{ml}$ of $P$. aeruginosa $\left(1 \mathrm{ml} \approx 1.5 \times 10^{9} \mathrm{CFU}\right)$ cultures were separately added. Each flask was augmented with 50 $\mu \mathrm{l}$ of DDT $5 \mathrm{mM}$ with a final concentration of 12.5 $\mu \mathrm{M}$. Besides, the volatilization of the substrate and provide aerobic conditions, oxygen was implemented and protected with a glass stopper. For the control treatment, three cultures were treated using an autoclave $\left(121^{\circ} \mathrm{C}, 20 \mathrm{~min}\right)$ to killed the fungal culture, subsequently the preparation process. Furthermore, all of the procedures were managed in triplicates. The cultures were incubated at $25^{\circ} \mathrm{C}$ for 7 days incubation. 
A comparison between the amount of DDT degradation by co-cultures and degradation by fungal and bacterial particulary was described by an optimization ratio to illustrate the existence of a synergistic relation between fungi and bacteria. After an additional incubation for 7 days, the culture was substituted with $50 \mu \mathrm{l}$ of pyrene $5 \mathrm{mM}$ to a final concentration of $12.5 \mu \mathrm{M} /$ flask. The cell debris was washed by added $20 \mathrm{ml}$ of methanol and $5 \mathrm{ml}$ of acetone and then homogenized following centrifuge at 3,024 $\times \mathrm{g}(10 \mathrm{~min})$ to remove the cells. The supernatant was filtered by a glass fiber filter. The organic fractions were collected by extraction with $200 \mathrm{ml} n$-hexane (Purnomo et al. 2010b). The organic fractions were dehydrated by using anhydrous sodium sulfate $\left(\mathrm{Na}_{2} \mathrm{SO}_{4}\right)$, evaporated, and diluted with methanol. The concentration of DDT recovery was estimated by analyzing the collected supernatant using HPLC (Shimadzu, Japan). The supernatant was analyzed using isocratic elution with $82 \%$ of methanol in $0.1 \%$ trifluoroacetic acid as a mobile phase at a flow rate of $1 \mathrm{ml} / \mathrm{min}$. Retention times of DDMU, DDE, and DDT were 11.3, 12.2, and $14.7 \mathrm{~min}$, respectively. The recovery of DDT and its metabolic products was calculated by compared the peak areas with pyrene. Undetected metabolite products by HPLC were further analyze using GCMS by dissolving the latter sample in $n$-hexane. The column (30-m fused DB-5MS, $0.25 \mathrm{~mm}$ diameter) was run with $\mathrm{He}$ (helium) at a steady flow rate of $1.0 \mathrm{ml}$ per min. The oven temperature was set at $80^{\circ} \mathrm{C}$ for $3 \mathrm{~min}$, continually increase to $320^{\circ} \mathrm{C}$ at $12^{\circ} \mathrm{C} \mathrm{min}^{-1}$. End temperatures were held at $300^{\circ} \mathrm{C}$ for 5 min (Purnomo 2017; Purnomo et al. 2019c).

\subsection{Interaction Assay of Fungal-Bacteria}

Pre-incubation of $P$. aeruginosa cultures were put $(20$ $\mathrm{ml}$ ) into tube, followed by centrifuged (10 min at 3,024 $\times g)$ to separate the dregs. The biomass was washed with $20 \mathrm{ml}$ of sterile demineralized water, homogenized, and centrifuged ( $10 \mathrm{~min}$ at $3,024 \times \mathrm{g}$ ) to get the bacterial cells. The fungal disk was placed at the center of the plate that contains PDA, at a distance of $3.5 \mathrm{~cm}$ from the fungal disk, the bacterial cells $(10 \mu \mathrm{l})$ were inoculated into the plate. The plate was incubated at $25^{\circ} \mathrm{C}$ in the dark. After day 4th of incubation, the mycelial growth was started to measure (Purnomo et al. 2019a).

\subsection{Statistical Analysis}

To demonstrate the significant differences between control and treatments, Student's t-test was used at a significance level of $\mathrm{p}<0.05$. Standard errors and mean values were also estimated. The analysis was accomplished using SPSS 22 program for Windows (SPPS Inc., USA; Rizqi and Purnomo 2017).

\section{Results}

\subsection{Interaction Assay}

The purpose of the confrontation assay experiment was to find out the interactions that occur between fungi and bacteria. As shown in Figure 1, there are diverse interactions between $P$. eryngii- $P$. aeruginosa (co-cultures) after 12 days of incubation. It is apparent from this Figure (2A and 2B) that P. eryngii could grow on the media which $P$. aeruginosa used $P$. eryngii mycelium to expand (yellow circle). P. aeruginosa did not have a significant effect on the growth of $P$. eryngii either on the line with bacterial confrontation $(0.39 \pm 0.06 \mathrm{~cm} /$ day) or on the line without bacterial confrontation $(0.41 \pm 0.02 \mathrm{~cm} /$ day $)$ compare with control $(0.38 \pm 0.04$ $\mathrm{cm} /$ day), there is no enhance or inhibit effects. These results indicate that there is no synergy relationship between $P$. eryngii and $P$. aeruginosa.
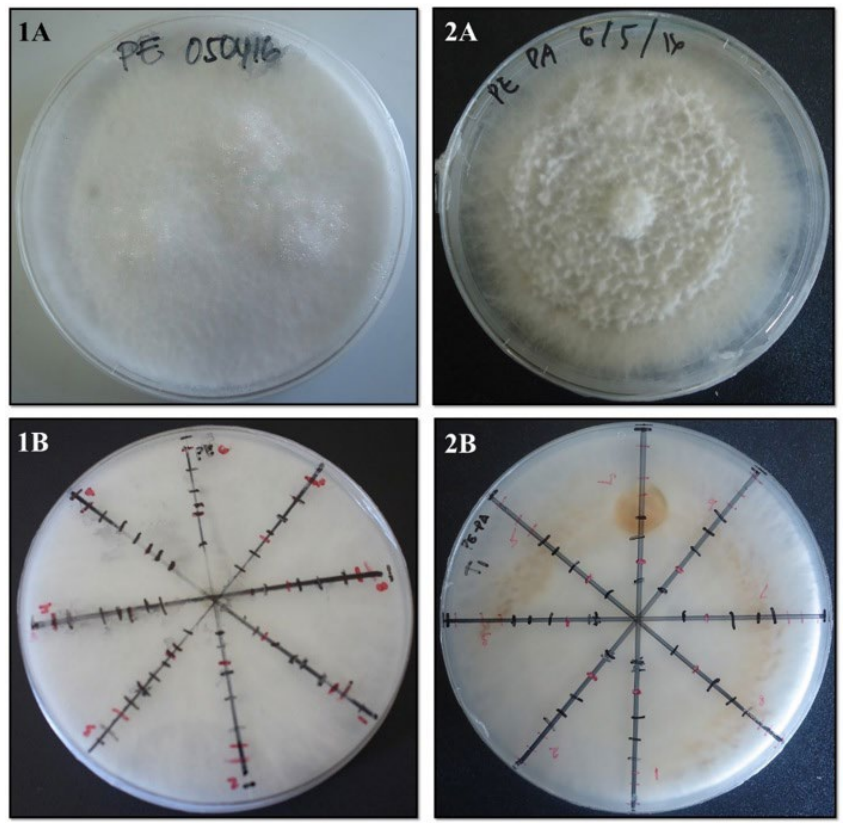

Figure 1. Growth of $P$. eryngii after 12 days incubation. (1A) culture without bacteria (control-front side), (2A) co-cultures of $P$. eryngii and P. aeruginosafront side, (1B) culture without bacteria (controlback side), (2B) co-cultures of $P$. eryngii and $P$. aeruginosa-back side 


\subsection{The Removal of DDT}

Biodegradation of DDT by co-cultures was additionally analyzed by co-culturing $P$. eryngii with $P$. aeruginosa. After 7 days of incubation, cocultures degraded approxymately $82 \%$ of DDT at concentrations $10 \mathrm{ml}$ (Table 1). These outcomes showed that the expansion of bacteria brought about an expanding DDT degradation rate by $P$. eryngii.

Figure 2 demonstrated the DDT degradation by the single culture of $P$. aeruginosa, and co-cultures $P$.

Table 1. Biodegradation of DDT in PDB medium during a 7-days incubation period

\begin{tabular}{|c|c|c|c|}
\hline \multirow{2}{*}{$\begin{array}{l}\text { Volume of } \\
\text { bacteria }\end{array}$} & \multicolumn{2}{|c|}{ DDT degradation (\%) } & \multirow{2}{*}{$\begin{array}{l}\text { Ratio of } \\
\text { Optimization } \\
\text { Co-culture }\end{array}$} \\
\hline & P. aeruginosa* & Co-culture & \\
\hline$\left(P\right.$. eryngii only) ${ }^{*}$ & $43.12 \pm 1.18$ & & \\
\hline $1 \mathrm{ml}$ & $75.17 \pm 2.06^{\mathrm{b}}$ & $33.11 \pm 1.98^{\mathrm{a}}$ & $0.26^{\mathrm{a}}$ \\
\hline $3 \mathrm{ml}$ & $82.13 \pm 2.34^{c}$ & $42.10 \pm 0.98^{\mathrm{b}}$ & $0.34^{\mathrm{b}}$ \\
\hline $5 \mathrm{ml}$ & $86.15 \pm$ & 72.22 & $0.56^{\mathrm{a}}$ \\
\hline $7 \mathrm{ml}$ & $90.20 \pm 0.16^{\mathrm{d}}$ & $71.34 \pm 3.09^{c}$ & $0.52^{\mathrm{c}}$ \\
\hline $10 \mathrm{ml}$ & $65.98 \pm 0.87^{a}$ & $82.37 \pm 3.48^{d}$ & $0.57^{c}$ \\
\hline
\end{tabular}

HPLC was used to evaluate the results. The data is presented as mean \pm S.D. $(n=3)$. No substantially different data on each column followed by the same lowercase ( $p<0.05) ; 1$ $\mathrm{ml}$ of $P$. aeruginosa $\approx 1.5 \times 10^{9} \mathrm{CFU}$ eryngii and $P$. aeruginosa. The addition of $P$. aeruginosa into culture $P$. eryngii had a different effect on the degradation of DDT. The addition of 1 and $3 \mathrm{ml}$ of $P$. aeruginosa decrease the degradation rate of DDT by P. eryngii. Additionally, the measure of degradation of DDT by $P$. eryngii was increased when added with $P$. aeruginosa at 5,7 , and $10 \mathrm{ml}$ compared with that without the inclusion of bacterium. The inclusion of $10 \mathrm{ml}$ of $P$. aeruginosa in $P$. eryngii culture brought about the most elevated degradation of DDT, about $82 \%$. On the opposite side, the debasement pace of DDT by co-cultures was lower than $P$. aeruginosa culture only. The ratio of optimization (RO) was used to express the effectivity of the co-cultures on the biodegradation process (Table 1 ). The co-cultures at $10 \mathrm{ml} P$. aeruginosa $(\mathrm{RO} \approx 0.57$ ) was selected for a further experiment on the variation of time and identification of metabolic products.

Figure 3 provides the experimental data of the difference of time adjunct of $P$. aeruginosa at $0,1^{\text {st }}$, $3^{\text {rd }}$, and $5^{\text {th }}$ days incubation. The variation of time addition bacteria into the fungal culture shows a fluctuating result, in which DDT degradation was approximately 71,4682 , and $65 \%$ at $0,1^{\text {st }}, 3^{\text {rd }}$, and

100.00

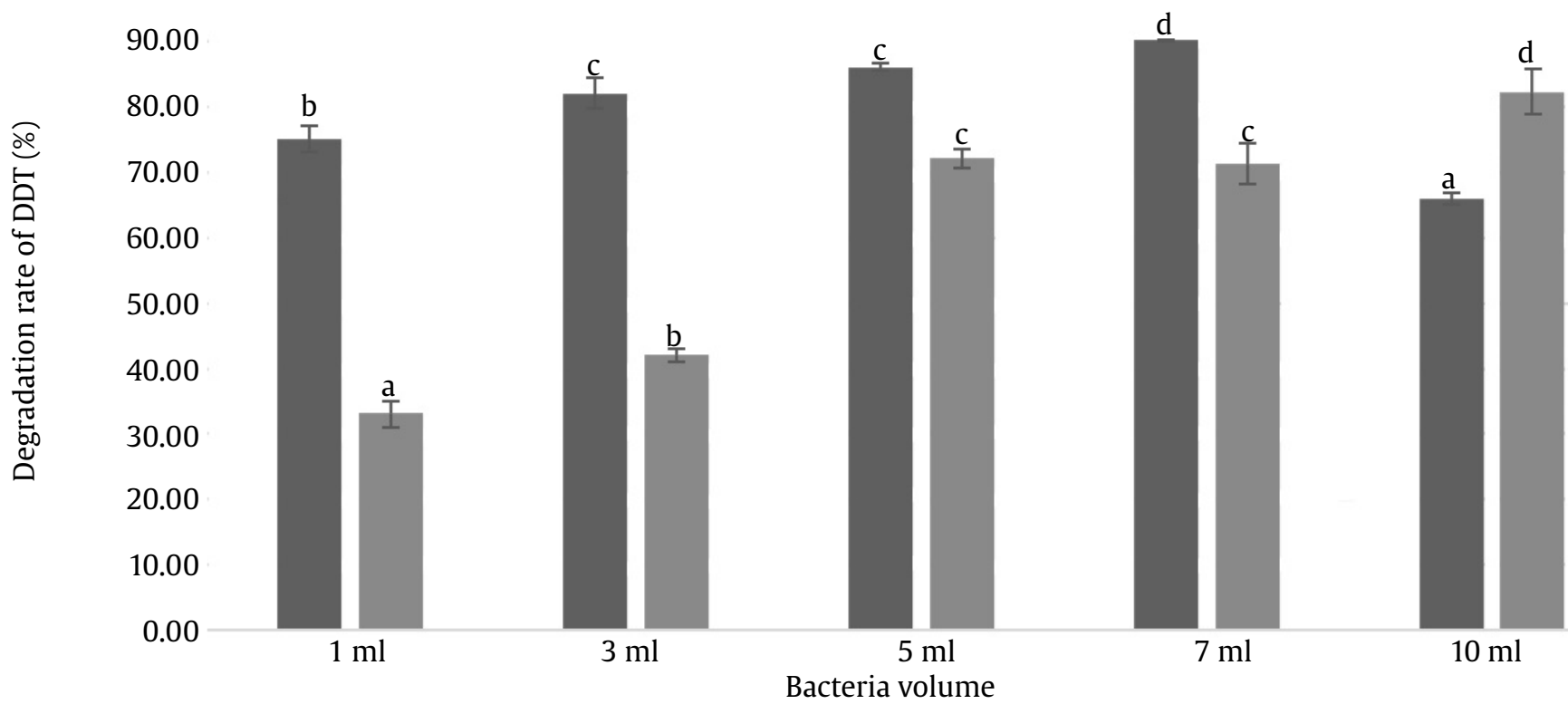

Figure 2. Effect of the addition of $P$. aeruginosa into P. eryngii culture in DDT degradation during 7 days of incubation. The data were determined by HPLC. Data are presented as mean and standard deviations $(n=3)$. The same lowercase letter on each bar indicates no significant differences $(\mathrm{p}<0.05)$ 


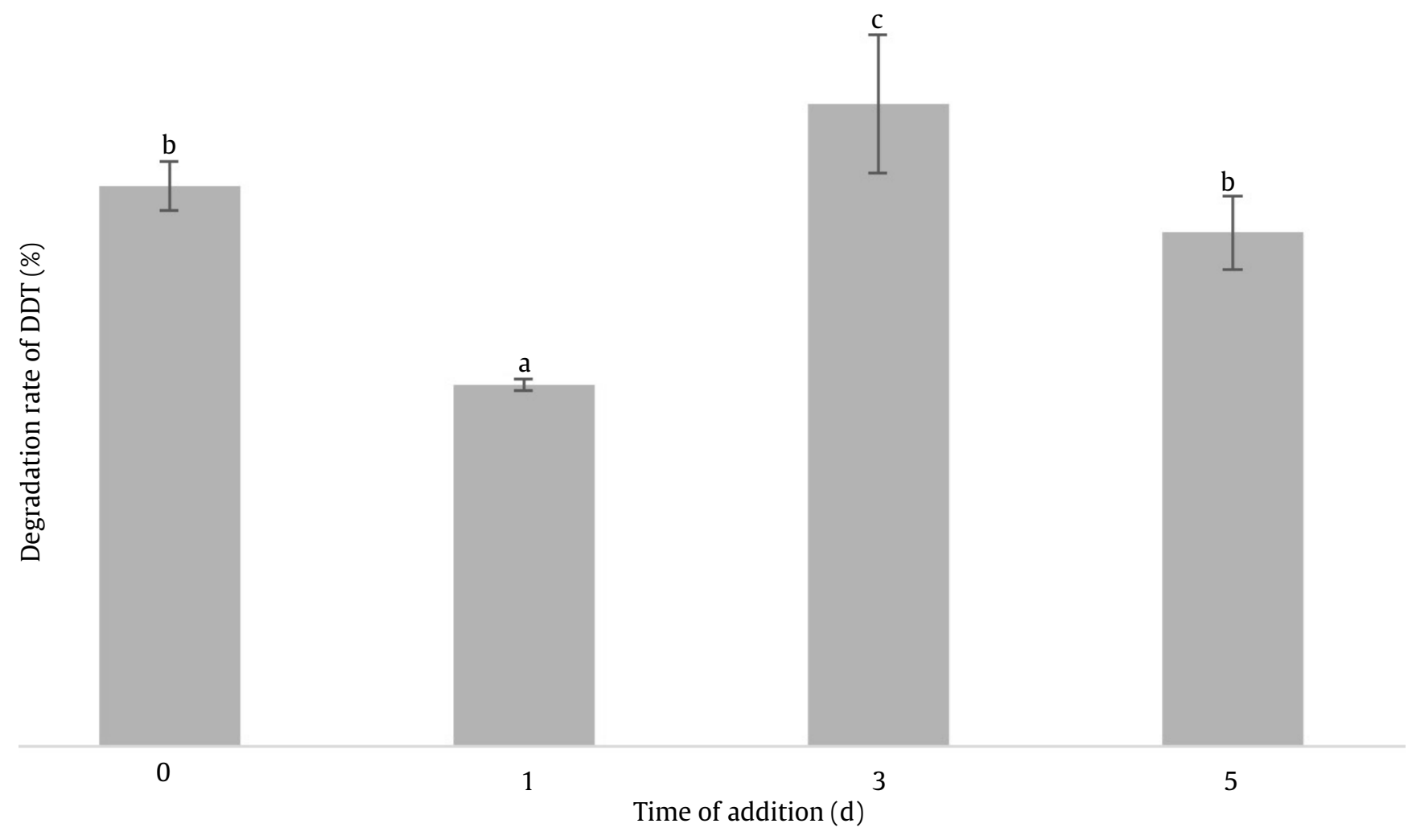

Figure 3. The effect of different time addition of P. aeruginosa on DDT degradation by co-cultures. HPLC was used to evaluate the results. The data was presented as mean \pm standard deviation $(n=3)$. No substantially different data on each bar followed by the same lowercase letter $(\mathrm{p}<0.05)$

$5^{\text {th }}$ days incubation, respectively. The lowest DDT degradation value was about $46 \%$ in co-cultures with the adjunct of bacteria on the first day (46\%), while the best adjunct time was on the fifth day (82\%).

To investigate the metabolites of DDT, co-cultures were incubated with $5 \mathrm{mM}$ of DDT for $7 \mathrm{~d}$. Figure 4 and 5 showed the products obtained from co-cultures which identified by GC-MS. The co-cultures resulted in DDE as a dominant metabolite and trace amount of DDD. These sorts of metabolites were not quite the same as the metabolites delivered by a single culture of $P$. eryngii and $P$. aeruginosa (data not shown). The transformation of DDT into DDE and DDMU was carried out by $P$. eryngii, while $P$. aeruginosa, forming DDT to DDD and DDMU, and co-cultures of $P$. eryngii and forming DDT to DDE.

To find out the DDT degradation pathway in cocultures, DDD and DDE were used as substrates (Table 2). However, the amount of recovery of each substrate did not match with the metabolites detected in HPLC. It is suspected, HPLC cannot detect some metabolites or the amount of metabolites was limited. DDD and DDE could be degraded approximately 8 and 53\% by co-cultures, respectively. This condition showed that the structure of DDD is quite difficult to be degraded by co-cultures. 


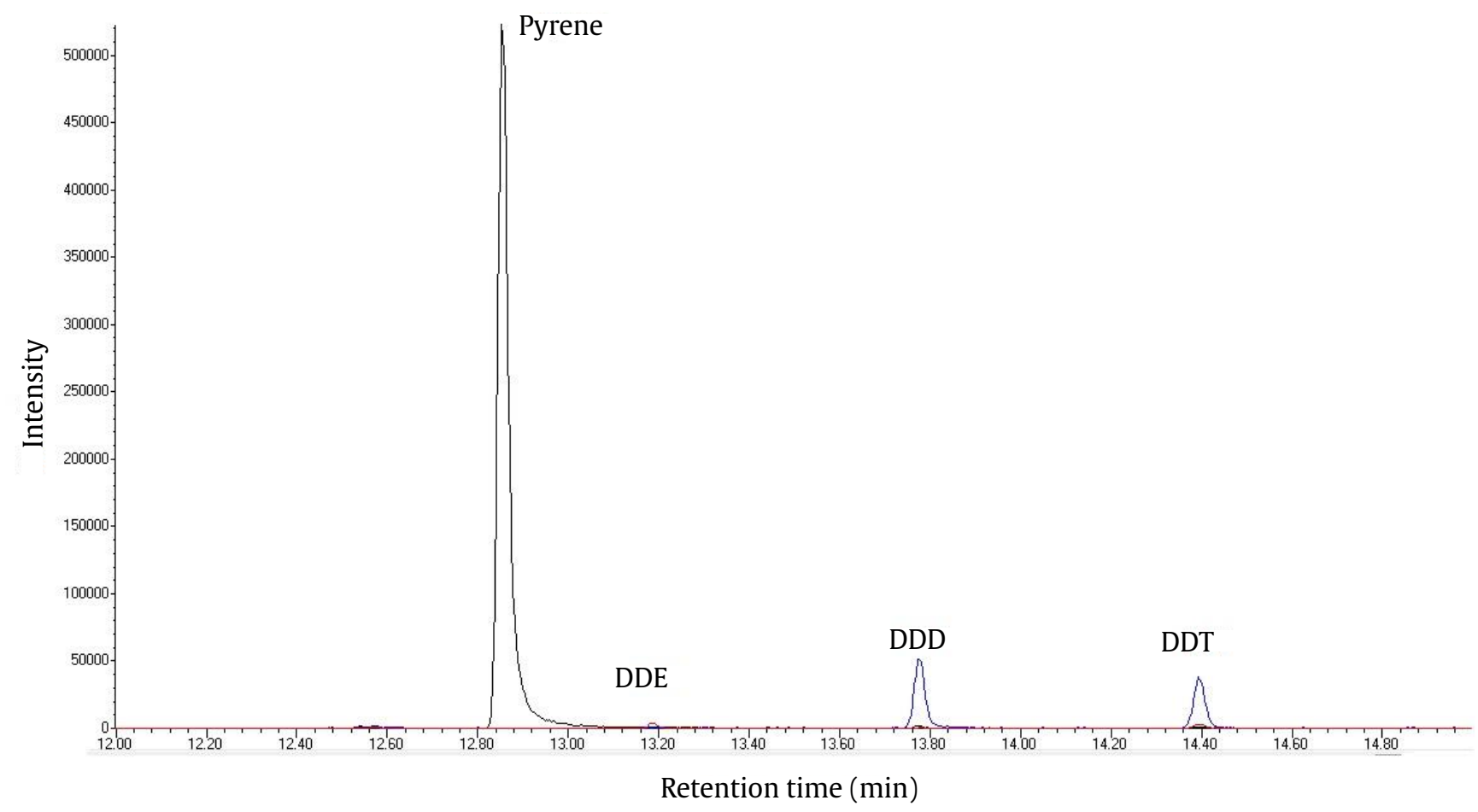

Figure 4. GC/MS chromatogram of DDT degradation by co-cultures of $P$. eryngii and $P$. aeruginosa<smiles>Cc1ccc(C(=C(Cl)Cl)c2ccc(Cl)cc2)cc1</smiles>

DDE<smiles>Clc1ccc(C(c2ccc(Cl)cc2)C(Cl)(Cl)Cl)cc1</smiles>

DDT<smiles>C=C=C</smiles>

DDD

Figure 5. Proposed pathway for DDT degradation by P. eryngii, P. aeruginosa, and co-cultures. P. eryngii single culture (thin black arrows), P. aeruginosa single culture (dotted arrows), co-cultures (open arrows)

Table 2. Recovery of DDT and metabolic products by cocultures of $P$. eryngii and $P$. aeruginosa

\begin{tabular}{llccc}
\hline Substrate & Degradation (\%) & \multicolumn{2}{c}{$\begin{array}{c}\text { Metabolic product } \\
\text { recovery }(\%)\end{array}$} & \multirow{2}{*}{ Total } \\
\cline { 3 - 4 } & & DDD & DDE & \\
\hline DDT & $82.37 \pm 3.48$ & 14.33 & 1.48 & 98.18 \\
DDD & $8.95 \pm 0.70$ & 87.75 & - & 96.70 \\
DDE & $53.66 \pm 10.49$ & - & 43.04 & 96.70 \\
\hline
\end{tabular}

HPLC was used to evaluate the results. The data is presented as mean \pm standard deviation $(\mathrm{n}=3)$.

\section{Discussion}

Bacteria and fungi have various interactions such as antagonistic, cooperative, synergistic, commensal, and symbiotic were often occur between the microorganisms (Frey-Klett et al. 2011).
In this current research, the confrontational assay of $P$. eryngii co-culturing with $P$. aeruginosa had not shown synergistic interaction. As shown in Figure 1, $P$. aeruginosa used the $P$. eryngii mycelium to grow (yellowish color and circle form); still, the growth of $P$. eryngii was average. In this case, $P$. eryngii gave positive interaction for $P$. aeruginosa because the colony of $P$. aeruginosa was spread without scratched the medium with bacteria. Bacteria are microorganisms which in the process of formation of colonies, are influenced by several factors are known as substrate texture, microstructure, and carbon content.

Bacteria are very dependent on the presence of water and usually adhere to the surface of microparticles or solid particles. In the soil 
environment, fungi and bacteria occupy the same space to grow. As a result, fungi and bacteria compete with each other to obtain sources of nutrients for cell growth and cause interactions between the two (Effmert et al. 2012). Based on this, a possible explanation for this current result might be that $P$. aeruginosa utilizes the surface of mycelium of $P$. eryngii to grow and obtain nutrients in the culture medium. P. aeruginosa also used $P$. eryngii as a vector for translocation (Kohlmeier et al. 2005).

Prior studies have noted the utilization of $P$. aeruginosa to produce biosurfactant (Kim et al. 2010; Nie et al. 2010; Zhang et al. 2012; Abbasi et al. 2012; Al-Wahaibi et al. 2014) and capable of degrading DDT (Bidlan and Manonmani 2002). In our previous study, $P$. aeruginosa has shown the potency to degrade DDT (Sariwati and Purnomo 2018), biodecolorization of methyl orange (Purnomo and Mawaddah 2020; Purnomo et al. 2020b), in a single culture or co-culturing with fungal. In the current research, co-culturing $P$. eryngii with $P$. aeruginosa significantly increase the biodegradation of DDT in 7 days incubation. Notably that $P$. eryngii culture only, degrade $48 \%$ of DDT in 7 days incubation. In general, therefore, it seems that biosurfactants produced by bacteria can reduce surface tension and increase the solubility and bioavailability of DDT in water (Wang et al. 2018).

A significant increment of DDT removal rate by $P$. eryngii was obtained after the addition of biosurfactant producing bacteria. The maximal DDT removal rate $(82.37 \%)$ was achieved in the co-cultures at a concentration of $10 \mathrm{ml}$ (Figure 1). The ability of particular bacterium or fungus to degrade DDT was not equivalent to its co-cultures. $P$. aeruginosa at 7 $\mathrm{ml}$ addition could degrade approxymately 90\% DDT. These results were higher than co-cultures (73\%). Cocultures at 1 and $3 \mathrm{ml}$, showed that the concentration of $P$. aeruginosa was limited to be able to enhance the DDT removal processed by $P$. eryngii. Another possibility was that $P$. aeruginosa and $P$. eryngii produce some metabolite that inhibits each other to degrade DDT (Wahyuni et al. 2016; Ramadhania et al. 2018; Sariwati et al. 2019). Generally, the addition of $P$. aeruginosa enhanced the degradation rate of DDT by $P$. eryngii, but there is no synergistic relationship between $P$. aeruginosa and $P$. eryngii.

The ratio of optimization (RO) is a well-established approach to ensure the synergistic interaction of fungal and bacteria. All of co-culture showed RO $<1$ (Table 1), which indicated that $P$. aeruginosa were not affected in increments of biodegradation of DDT in co-cultures, because the levels of DDT degradation in single culture was higher than co-cultures. This finding is contrary to previous studies, which have suggested that $P$. eryngii and $R$. pickettii have a synergistic interaction with RO $>1$ (Purnomo et al. 2019a).

The variation of time addition of bacteria in $P$. eryngii culture resulted in different degradation rates of DDT. The proliferation of $P$. aeruginosa bacterium at other incubation times influenced increasing the biodegradation ability of DDT by $P$. eryngii. The $P$. eryngii single culture was only able to degrade DDT by $48 \%$ during 7 days of incubation. Still, by the addition of $P$. aeruginosa at the beginning of incubation, the degradation rate was $70 \%$. The degradation increased in third-day addition bacteria, with a degradation rate of approximately $80 \%$, but a decrease in the first day and fifth day of addition bacteria. Mentioned the variable of a medium that affected the rate of biodegradation as an example of the obtainability of a xenobiotic compound to the microorganisms, physiological mechanisms of the microorganisms the ability to survive and produce cells by utilizing xenobiotic compounds, and sustainable population of the microorganisms (Purnomo et al. 2019b; Khumaidah et al. 2019). Based on this, at the beginning of the incubation, the rate of biodegradation is strongly influenced by the presence of bacteria. P. aeruginosa bacteria were able to utilize the availability of DDT in the media as a source of nutrients to increase the biodegradation of DDT by $P$. eryngii. The decrease of DDT degradation on the first day of incubation suggested caused by $P$. aeruginosa was unable to regenerate cells or unable to survive due to the presence of $P$. eryngii. According to Li et al. (2014), P. eryngii, in its growth phase, produced sulfated polysaccharides that could damage the cell walls and bacterial cytoplasmic membrane (Putri et al. 2018; Ramadhania et al. 2019; Auwaliyah et al. 2019). The increasing of DDT degradation on day 3 of incubation, DDT was partially degraded by $P$. eryngii, after the addition of $P$. aeruginosa, DDT was available to lessen by bacteria.

\subsection{Metabolite Analysis and Degradation Pathway}

Our previous study showed DDE and DDMU were metabolite products of DDT degradation by P. eryngii (Purnomo et al. 2019a). At the same time, DDD and 
DDMU were products of DDT biodegradation by P. aeruginosa (Boelan and Purnomo 2019). In this current research, after $7 \mathrm{~d}$ of incubation, metabolite analysis by GCMS and HPLC showed the addition of $P$. aeruginosa $(10 \mathrm{ml})$ could transform DDT into some metabolites such as DDE and DDD (Figure 4). This finding is contrary to previous co-cultures studies, which suggested that co-culturing of $P$. eryngii and $R$. pickettii could transform DDT into DDE, DDD, and DDMU (Purnomo et al. 2019a). This inconsistency may be due to the different interactions that occur between bacteria and fungi. Although $P$. aeruginosa used $P$. eryngii as a vector to mobilize, $P$. eryngii hyphal growth was unstimulated by bacterial metabolites. Several relationships between bacteria and fungi must be considered from various perspectives. Co-cultures of Penicilium sp. and three strains of bacterial (Burkholderia cepacea, R. pickettii, and $P$. aeruginosa) showed a synergistic effect on the elimination of phenanthrene, approximately $68-73 \%$ in 18 days (Chávez-Gómez et al. 2003). In comparison, a co-culture of biofilm of Penicillium frequentans and Bacillus mycoides confirmed an ability to degrade polyethylene (Gou et al. 2009). Bacteria and fungal had various mechanism of DDT transformation into others metabolite. Degradation mechanism of DDT by $P$. aeruginosa through reductive dichlorination of DDT to DDD, and meta ring cleavage mechanism. Whiterot fungal species transform DDT trough reductive chlorination, transformation, and mineralization into some metabolite product (Foght et al. 2001). The proposed pathway was shown in Figure 5. Co-cultures transformed DDT to DDE through the elimination of chloride ion and transformed DDT to DDD to through reductive dechlorination.

\section{References}

Abbasi H et al. 2012. Biosurfactant-producing bacterium, Pseudomonas aeruginosa MA01 isolated from spoiled apples: physicochemical and structural characteristics of isolated biosurfactant. J Biosci Bioeng 113:211-219.

Al-Wahaibi et al. 2014. Biosurfactant production by Bacillus subtilis B30 and its application in enhancing oil recovery. Colloids Surfaces B Biointerfaces 114:324333.

Auwaliyah F et al. 2019. Antioxidant and antibacterial activities of Ischaemum indicum leaves extracted using different solvents. Malaysian Journal of Fundamental and Applied Sciences 15:436-440.

Bidlan R, Manonmani HK. 2002. Aerobic degradation of dichlorodiphenyltrichloroethane (DDT) by Serratia marcescens DT-1P. Process Biochem 38:49-56.
Boelan EG, Purnomo AS. 2019. Biodegradation of 1,1,1-trichloro-2,2-bis (4-chlorophenyl) ethane (DDT) by mixed cultures of white-rot fungus Ganoderma lingzhi and bacterium Pseudomonas aeruginosa. HAYATI J Biosci 26:90-95.

Boelan EG, Purnomo AS. 2018. Abilities of co-cultures of white-rot fungus Ganoderma lingzhi and Bacteria Bacillus subtilis on biodegradation DDT.J Phys Conf Ser 1095:1-7.

Chávez-Gómez B et al. 2003. Removal of phenanthrene from soil by co-cultures of bacteria and fungi pregrown on sugarcane bagasse pith. Bioresour Technol 89:177-183.

Effmert Uet al. 2012. Volatile mediated interactions between bacteria and fungi in the Soil. J Chem Ecol 38:665-703.

Foght et al.2001. Bioremediation of DDT-contaminated soils: a review. Bioremediation Journal 5:225-246.

Frey-Klett P et al. 2011. Bacterial-fungal interactions: hyphens between agricultural, clinical, environmental, and food microbiologists. Microbiol Mol Biol Rev 75:583609.

Gilligan PH et al. 2003. Burkholderia, Stenotrophomonas, Ralstonia, Brevundimonas, Comamonas, Delftia, Pandoraea, and Acidovorax. In: Murray PR. Baron EJ. Jorgensen JH, Pfaller MA, Yolken RH 8th (Eds.). Washington DC: Manual of Clinical Microbiology.

Gonzalez M et al. 2018 Role of a non-ionic surfactant and carboxylic acids on the leaching of aged DDT residues in undisturbed soil columns. Journal of Soil and Sediments 19:1745-1755

Gou M et al. 2009 Azo dye decolorization by a new fungal isolate, Penicillium sp. QQ and fungal-bacterial cocultures. J Hazard Mater 170:314-319.

Huang Y, Wang J. 2013. Degradation and mineralization of DDT by the ectomycorrhizal fungi, Xerocomus chrysenteron. Chemosphere 92:760-764.

Khumaidah L et al. 2019. Antimicrobial activity of Sonneratia ovata backer. HAYATI J Biosci 26:152-155.

Kim P Il et al. 2010. Production of biosurfactant lipopeptides iturin A, fengycin, and surfactin A from Bacillus subtilis CMB32 for control of Colletotrichum gloeosporioides. J Microbiol Biotechnol 20:138-145

Kohlmeier S et al. 2005. Taking the fungal highway: mobilization of pollutant-degrading bacteria by fungi. Environ Sci Technol 39:4640-4646.

Li et al. 2014. Antioxidant and antibacterial activities of sulphated polysaccharides from Pleurotus eryngii and Streptococcus thermophilus ASCC 1275. Food Chemistry 165:262-270.

Nawfa R et al. 2019. Synthesis of antibiotic penicillin-g enzymatically by Penicillium chrysogenum. Asian Jurnal of Chemistry 31:2367-2369.

Nie M et al. 2010. Novel rhamnolipid biosurfactants produced by a polycyclic aromatic hydrocarbon-degrading bacterium Pseudomonas aeruginosa strain NY3. Biotechnol Adv 28:635-643.

Purnomo AS et al. 2008. Degradation of 1,1,1-trichlro-2,2-bis (4-chlorophenyl) ethane (DDT) by brown-rot fungi. Journal of Bioscience and Bioengineering 105:614-621.

Purnomo AS et al. 2010a. Application of mushroom waste medium from Pleurotus ostreatus for bioremediation of DDT-contaminated soil. Int Biodeterior Biodegrad 64:397-402.

Purnomo AS et al. 2010b. DDT degradation potential of cattle manure compost. Chemosphere 80:619-624.

Purnomo AS et al. 2010c. Involvement of fenton reaction in DDT degradation by brown rot fungi. International Biodeterioration and Biodegradation 64:560-565.

Purnomo AS et al. 2011a. Bioremediation of DDTcontaminated soil by brown-rot fungi. International Biodeterioration and Biodegradation 65:691-695. 
Purnomo AS et al. 2011b. Basic studies and applications on bioremediation of DDT: a review. International Biodeterioration and Biodegradation 65:921-930.

Purnomo AS et al. 2013. Biotransformation of heptachlor and heptachlor epoxide by white-rot fungus Pleurotus ostreatus. International Biodeterioration and Biodegradation 82:40-44.

Purnomo AS et al. 2014. Biodegradation of heptachlor and heptachlor epoxide-contaminated soils by white-rot fungal inocula. Environmental Science and Pollution Research 21:11305-11312.

Purnomo AS. 2017. In Microbe-assisted degradation of aldrin and dieldrin. In: Singh SN (Eds.). Switzerland: Springer Nature. pp. 1-22.

Purnomo AS, Fajriah. 2017. Pengaruh penambahan Bacillus subtilis pada biodegradasi DDT oleh Phlebia brevispora. Akta Kim 2:58-65.

Purnomo AS et al. 2017a. Evaluation of the synergistic effect of mixed cultures of white-rot fungus Pleurotus ostreatus and biosurfactant-producing bacteria on DDT biodegradation. Journal of Microbiology and Biotechnology 27:1306-1315.

Purnomo AS et al. 2017b. Biodegradation of aldrin and dieldrin by the white-rot fungus Pleurotus ostreatus. Curr Microbiol 74:320-324.

Purnomo AS et al. 2019a. Ralstonia pickettii enhance the DDT biodegradation by Pleurotus eryngii. J Microbiol Biotechnol 29:1424-1433.

Purnomo AS et al. 2019b. Bio-decolorization and novel biotransformation of methyl orange by brown-rot fungi. International Journal of Environmental Science and Technology 16:7555-7564.

Purnomo AS et al. 2019c. The use of Ralstonia pickettii for biodegradation of crude oil under high salinity medium. Malaysian Journal of Fundamental and Applied Sciences 15:377-380.

Purnomo AS, Mawaddah MO. 2020. Biodecolorization of methyl orange by mixed cultures of brown-rot fungus Daedalea dickinsii and bacterium Pseudomonas aeruginosa. Biodiversitas 21:2297-2302.

Purnomo AS et al. 2020a. Synergistic interaction of a consortium of the brown-rot fungus Fomitopsis pinicola and the bacterium Ralstonia pickettii for DDT biodegradation. Heliyon 6:e04027.

Purnomo AS et al. 2020b. Fenton reaction involvement on methyl orange biodegradation by brown-rot fungus Gloeophyllum trabeum. In: The 14th Joint Conference on Chemistry 2019. Solo: AIP Conf Proc. pp. 1-6.

Purnomo AS et al. 2020c. Culture of bacterium Bacillus subtilis as degradation agent for sea water remediation Contaminated by Petroleum.Journal of The Indonesian Chemical Society 3:53-58.

Putri DA et al. 2018. Antioxidant and antibacterial activities of Ananas comosus peel extracts. Malaysian Journal of Fundamental and Applied Sciences 14:307-311.

Ramadhania NR et al. 2018. Antibacterial activities of Syzygium polyanthum wight leaves. In: The 3rd International Seminar on Chemistry. Surabaya: AIP Conference Proceedings. pp. 1-6.
Ramadhania NR et al. 2019. Anti-oxidant and anti-bacterial activities of Anthurium plowmanii leaves extracts. Malaysian Journal of Fundamental and Applied Sciences 15:194-299.

Rios LE et al. 2012. Use of surfactants and blends to remove DDT from contaminated soils. The Canadian Journal of Chemical Engineering 91:238-244.

Rizqi HD, Purnomo AS. 2017. The ability of brown-rot fungus Daedalea dickinsii to decolorize and transform methylene blue dye. World Journal Microbiology and Biotechnology 33:92.

Sari AA et al. 2013. Enhancement of ligninolytic activity of Trametes versicolor u97 pre-grown in agricultural residues to degrade DDT in soil. Water Air Soil Pollut 224:1616

Sariwati A et al. 2017. Abilities of co-cultures of brown-rot fungus fomitopsis pinicola and Bacillus subtilis on biodegradation of DDT. Current Microbiology 74:10681075.

Sariwati A, Purnomo AS. 2018. The effect of Pseudomonas aeruginosa addition by brown-rot fungus Fomitopsis pinicola. Indones J Chem 18:75-81.

Sariwati A et al. 2019. Phytochemical, antibacterial and antioxidant activities of Anthurium Hookerii leaves extracts. HAYATI J Biosci 26:101-109.

Setyo et al. 2018. Effects of bacterium Ralstonia pickettii addition on DDT biodegradation by Daedalea dickinsii. Research Journal of Chemistry and Environment 22:151156.

Sudaryanto A et al. 2007. Chapter 13 persistent toxic substances in the environment of Indonesia. Dev Environ Sci 7:587-627.

Teh ZC, Hadibarata T. 2014. Enhanced degradation of pyrene and metabolite identification by Pleurotus eryngii F032. Water Air Soil Pollut 225:1-8.

Villa RD et al. 2010. Soil remediation using a coupled process: soil washing with surfactant followed by photo-fenton oxidation. Journal of Hazardous Material 174:770-775.

Wang X et al. 2018. Surfactant-enhanced bioremediation of DDTs and PAHs in contaminated farmland soil surfactant-enhanced bioremediation of DDTs and PAHs in contaminated farmland soil. Environ Technol 39:1733-1744.

Wahyuni S et al. 2016. Purification and characterization of thermostable chitinase from bacillus SW41 for chitin oligomer production. Asian Journal of Chemistry 28:2731-2736

Wahyuni S et al. 2017. Characterization of mannanase isolated from corncob waste bacteria. Asian Journal of Chemistry 29:1119-1124.

Xiao Petal.2011. Anovel metabolic pathway for biodegradation of DDT by the white rot fungi, Phlebia lindtneri and Phlebia brevispora. Biodegradation 22:859-867.

Zhang $\mathrm{X}$ et al. 2012. Isolation and identification of biosurfactant producing and crude oil degrading Pseudomonas aeruginosa strains. Chem Eng J 209:138146.

Zheng G et al. 2012. Oil-in-water microemulsions enhance the biodegradation of DDT by Phanerochaete chrysosporium. Bioresour Technol 126:397-403. 